\title{
'We can Only Teach from Our Own Experience': From Emotional Learning in Childhood and Adolescence to Emotional Training in Teachers
}

Konstanze Schoeps ${ }^{1}$, Silvia Postigo ${ }^{2}$ and Inmaculada Montoya-Castilla ${ }^{{ }^{*}}$

${ }^{1}$ Department of Personality, Assessment and Psychological Treatment, University of Valencia, Spain

${ }^{2}$ Departmentof Psychology, Faculty of Health Science, European University of Valencia, Spain

\section{What is the Importance of Emotional Abilities?}

The ability to understand and process emotional information is an important part of human functioning as it facilitates an adequate adjustment to the environment [1]. The development of emotional abilities, including the capacity to perceive, use, understand and manage emotions underlies social competence and performance [2]. For instance, accurate perception of another person's emotional state enhances the estimation and understanding of their intention and subsequent behavior, making it easier to respond accordingly [3]. Emotions can facilitate thought processes reinforces learning, concentration, and execution [4]. Understanding the meaning of emotions in a social context guides decision-making, problem solving and reasoning [5]. Managing emotions effectively is the key to interpersonal relationships of good quality, due to the ability to express and behave in socially acceptable manners [2]. Furthermore, these emotional skills have been associated with physical and mental health, psychological well-being, as well as academic and work success [6].

\section{Why is it Important to Teach and Learn Emotional Abilities in Schools?}

Emotional abilities are thought to be, emotional abilities are fundamental to human development and well-being. Many children and adolescents struggle with peer relationships and school tasks because they have trouble describing and expressing their feelings accurately, independent of the context where these feelings have arisen. With regard to the school context, a lot of disruptive and aggressive behaviors among students such as bullying may be partially attributed to a deficit in their social and emotional development [7]. They may engage in disruptive behavior in order to achieve social acceptance [8]. Thus, students must learn to identify their feelings and those of others to increase their emotional understanding and management of unpleasant emotions such as anger, fear or disappointment, which are usually present in classroom conflicts. It seems evident that teaching children these emotional abilities is as important as any traditional academic subject; therefore emotional literacy should be a part of every school curriculum. For this reason, over the past few decades, many emotional learning programs have been developed in a variety of different cultural and academic contexts, using different theoretical and methodological approaches [9-11].

\section{How has our Research Group Contributed to the Research in this Field?}

For the past decade, the purpose of our research has been the study of social and emotional development in children and adolescents and, more recently, our focus has turned to the design and implementation of emotional education programs in the Spanish schools. Our research group EMINA-Emotional Education in Children and Adolescents, is linked to the University of Valencia and lead by full professor Remedios González Barrón and Professor Inmaculada Montoya Castilla. The members of our research group have been

\section{Publication History:}

Received: September 27, 2018

Accepted: October 22, 2018

Published: October 24, 2018

\section{Keywords:}

Social and emotional learning, Children and adolescent development, School-based intervention, Teacher training

collaborating with researchers studying these topics successfully in other cultural contexts, for instance, professor Carolyn Rieffe from Leiden University in the Netherlands, Professor Diana Raufelder from the University of Greifswald in Germany and Professor Elvira Cicognani from the University of Bolonia in Italy. With funding from the Spanish Government and the Valencian Regional Government, our work combines basic research in the assessment of child and adolescent development with applied research on designing and implementing intervention programs in an educational context. We published several articles about the psychometric properties of measurements designed for children and adolescents [12-13] in order to provide reliable and valid assessment of emotional development for the Spanish population. Furthermore, our results indicate a strong relationship between emotional development and young people's psychological, social and academic adjustment $[14,15]$ and well-being [16], as well as it's association with psychological maladjustment and stress has been established $[17,18]$. Based on these findings, which highlight the importance of children's social and emotional development to prevent psychological problems and enhance wellbeing during childhood and adolescence, we designed, implemented and published an effective school-based emotional education program: PREDEMA "from emotion to meaning" [19].

\section{Emotional Education Program for Children and Adolescents}

The PREDEMA program was designed for adolescents with the main objective to develop their emotional skills and abilities, in order to improve coexistence classroom and enhance student's wellbeing. Mayer and Salovey's model of emotional intelligence provides the theoretical framework to the program, explaining the cognitive and affective mechanisms that are involved in the development of social and emotional competence [20]. The model comprises four emotional abilities, which are built on one another in this order:

"Corresponding Author: Dr. Inmaculada Montoya-Castilla, Department of Personality, Assessment and Psychological Treatment, University of Valencia, Av. Blasco Ibañez 21, 46020 Valencia, Spain; E-mail: inmaculada.montoya@uv.es

Citation: Schoeps K, Postigo S, Montoya-Castilla I (2018) 'We can Only Teach from Our Own Experience': From Emotional Learning in Childhood and Adolescence to Emotional Training in Teachers. Int J Psychol Behav Anal 4: 153. doi: https://doi. org/10.15344/2455-3867/2018/153

Copyright: (C) 2018 Schoeps et al. This is an open-access article distributed under the terms of the Creative Commons Attribution License, which permits unrestricted use, distribution, and reproduction in any medium, provided the original author and source are credited. 
Citation: Schoeps K, Postigo S, Montoya-Castilla I (2018) 'We can Only Teach from Our Own Experience': From Emotional Learning in Childhood and Adolescence to Emotional Training in Teachers. Int J Psychol Behav Anal 4: 153. doi: https://doi.org/10.15344/2455-3867/2018/153

Page 2 of 3

perceiving emotion, facilitating thought using emotion, understanding, and managing emotion [21]. Besides, the program considers three additional educational approaches which are especially relevant for the work with adolescents: (1) promote meaningful learning, emphasizing adolescents' search for meaning and identity; (2) educate in human values such as responsibility, and tolerance; and (3) encourage the dialogue between adolescents and the surrounding world, including the classroom.

The program consists of eleven sessions, 50-minute sessions, which can be carried out during one or two trimesters (between two and six months) in weekly tutoring sessions with the teacher. Moreover, the program provides some supplementary sessions that can serve as alternative or additional activites, adapting the program to an specific group or increase the duration of the program. Students engage in the program by experimenting and learning about the four emotional competences proposed by Mayer and Salovey [20], following the same sequence of work in each session: (1) exploring the objective of the session through an experiential activity, such as role-playing or selfobservation; (2) creating symbolic representations of what has been learned and integrating it into previous knowledge by sharing the experience with other peers; (3) transferring what has been learned to other contexts by thinking of examples and real world applications. Results from our intervention study showed that the emotional education program was effective for promoting peer coexistence in the classroom by reducing bullying behavior and improving life satisfaction of adolescents in a quasi-experimental design [22]. These findings suggest that implementing classroom intervention programs to develop students' emotional competencies could be beneficial for their mental health and well-being. The complete protocol, including the activities proposed for every session, was published along with the results from the feasibility study [19], so teachers may use the book as a manual to implement emotional education in their classrooms. It might be beneficial for teachers to engage in emotional training themselves before teaching students about social and emotional abilities. For this purpose, we designed an educational training for teachers: MADEMO "experiencing to transmit".

\section{Emotional Training Program for Teachers}

Teachers have been showing great interest in learning more about emotional skills and abilities themselvesas they recognize the benefits that these competences might have not only for their students but for their own professional development. With the support from the Valencian Centre of Teacher's Permanent Professional Training, we offered the emotional training as part of teachers' professional development classes. The training comprised seven two-hour sessions, which were scheduled once a week two and a half months. The MADEMO program is a modified version of the PREDEMA program, which is tailored to the educators and their specific needs. The main objective is to train teacher's emotional skills and abilities to reduce work-related stress and enhance well-being. Results from our intervention study indicated that the emotional training was effective in promoting teachers' mental health by reducing work-related stress and emotional symptoms. Their well-being improved by enhancing self-esteem and life satisfaction. Currently, we are working on a book proposal about the MADEMO program in order to make it accesible to all teachers and educators, who are interested in emotional selfdevelopment and personal growth. Given the effectiveness of our emotional education programs, we are exploring how to incorporate new technology and family participation.

\section{New Challenges in the Digital World and Future Research}

New Information and Communication Technologies (ICTs) such as smartphones and tablets have generated multiple impacts in our society, for instance how people relate and interact with each other; being especially true for children and adolescents, the so-called "new digital generation" [23]. ICTs are an essential element in our daily lives, as they have become an important tool for socialization, learning and communicating with each other. Therefore, we are currently working on different ways to include ICTs in our emotional education programs in order to provide teachers with an attractive tool they can easily use to engage students in social and emotional development. In addition, the level of student engagement would increase if everybody in their environment, including parents and other family members, participate in the social and emotional development experience. For this new project we are also motivated to bring emotional training to families through parent workshops online or at school. Our future goal is to teach and train emotional skills from kindergarten to high school or even higher education in order to guarantee student, parent and teacher's mental health, well-being and life success.

\section{Competing Interests}

The authors declare that they have no competing interests.

\section{References}

1. LeDoux JE (2000) Emotion circuits in the brain. Annu Rev Neurosci 23: 155184.

2. Brackett MA, Rivers SE, Shiffman S, Lerner N, Salovey P, et al. (2006) Relating emotional abilities to social functioning: A comparison of self-report and performance measures of emotional intelligence. J Pers Soc Psychol 91: 780-795.

3. Elfenbein HA, Marsh AA, Ambady N (2002) Emotional intelligence and the recognition of emotion from facial expressions. The wisdom in feeling: Psychological processes in emotional intelligence. New York, NY: Guilford Press.

4. Mayer JD, Roberts RD, Barsade SG (2008) Human abilities: emotional intelligence. Annu Rev Psychol 59: 507-536.

5. Fernández-Berrocal P, Extremera N, Lopes PN, Ruiz-Aranda D (2014) When to cooperate and when to compete: Emotional intelligence in interpersonal decision-making. Journal of Research in Personality 49: 21-24.

6. Marikutty PJ, Joseph MI (2016) Effects of emotional intelligence on stress, psychological well-being, and academic achievement of adolescents. Indian Journal of Health \& Wellbeing 7: 699-702.

7. Peachey AA, Wenos J, Baller S (2017) Trait emotional intelligence related to bullying in elementary school children and to victimization in boys. OTJR 37: 178-187.

8. García-Sancho E, Salguero JM, Fernández-Berrocal P (2017) Ability emotional intelligence and its relation to aggression across time and age groups. Scand J Psychol 58: 43-51.

9. Di Fabio A, Kenny ME (2016) Promoting well-being: The contribution of emotional intelligence. Front Psychol 7: 1-13.

10. Garaigordobil M, Peña-Sarrionandia A (2015) Effects of an emotional intelligence program in variables related to the prevention of violence. Front Psychol 6: 1-11.

11. Torrente C, Rivers SE, Brackett MA (2016) Teaching Emotional Intelligence in Schools: An Evidence-Based Approach. Springer International Publishing.

12. Górriz AB, Prado-Gascó VJ, Villanueva L, González-Barrón R (2015) Psychometric properties of the Somatic Complaints Scale in Spanish children and adults. Psicothema 27: 269-276.

13. Ordóñez A, Prado-Gascó VJ, Villanueva L, González R (2016) Propiedades psicométricas del Cuestionario de conciencia emocional en población infantil española. Revista Latinoamericana de Psicología 48: 183-190. 
Citation: Schoeps K, Postigo S, Montoya-Castilla I (2018) 'We can Only Teach from Our Own Experience': From Emotional Learning in Childhood and Adolescence to Emotional Training in Teachers. Int J Psychol Behav Anal 4: 153. doi: https://doi.org/10.15344/2455-3867/2018/153

Page 3 of 3

14. Montoya-Castilla I, Prado-Gascó V, Villanueva-Badenes L, González-Barrón R (2016) Adaptación en la infancia: Influencia del estilo parental y del estado de ánimo / Childhood adjustment: The effects on parenting styles on mood states. Acción Psicológica 13: 15-30.

15. Ordóñez-López A, González-Barrón R, Montoya-Castilla I (2016) Conciencia emocional en la infancia y su relación con factores personales y familiares. Revista de Psicología Clínica Con Niños Y Adolescentes 3: 79-85.

16. Schoeps K, Tamarit A, González R, Montoya-Castilla I (2018) Las competencias emocionales y la autoestima en la adolescencia: impacto sobre el ajuste psicológico. Revista de Psicología Clínica Con Niños Y Adolescentes, en prensa.

17. Ordóñez A, Maganto C, González R (2015) Somatic complaints, emotional awareness and maladjustment in schoolchildren. Anales de Pediatría 82 308-315.

18. Villanueva L, Montoya-Castilla I, Prado-Gascó V (2017) The importance of trait emotional intelligence and feelings in the prediction of perceived and biological stress in adolescents: Hierarchical regressions and fsQCA models. Stress 20: 355-362.

19. Montoya-Castilla I, Postigo S, González R (2016) Programa de educaión emocal para adolescentes: De la emoción al sentido (PREDEMA). Madrid: Pirámide.

20. Mayer JD, Salovey $P$ (1997) What is emotional intelligence? Emotiona development and emotional intelligence: implications for educators. New York: Basic Books.

21. Mayer JD, Caruso DR, Salovey P (2016) The Ability Model of Emotional Intelligence: Principles and Updates. Emotion Review 8: 290-300.

22. Schoeps K, Villanueva L, Prado-Gascó VJ and Montoya-Castilla I (2018) Development of Emotional Skills in Adolescents to Prevent Cyberbullying and Improve Subjective Well-Being. Front Psychol 9: 2050.

23. Schoeps K, Tamarit A, González R, \& Montoya-Castilla I (en prensa) Las competencias emocionales y la autoestima en la adolescencia: impacto sobre el ajuste psicológico. Revista de Psicología Clínica con Niños y Adolescente. 